\title{
Advances in Telehealth and Behavioral Assessment and Intervention in Education: Introduction to the Special Issue
}

\section{Mandy Rispoli ${ }^{1} \cdot$ Wendy Machalicek ${ }^{2}$}

Published online: 13 April 2020

(c) Springer Science+Business Media, LLC, part of Springer Nature 2020

\begin{abstract}
The purpose of these two volume special issues on the use of telehealth in behavioral assessment and intervention is to share research that advances our understanding of the utility of telehealth in behavioral education and considerations for use. Eleven articles spanning synthesis, single-case deigns, group experimental designs and case studies illustrate the growth in the application of telehealth to behavioral assessment and intervention across educational settings and providers. These eleven articles highlight the potential benefit of telehealth in providing access to high-quality behavioral assessment and intervention across home, school and center-based contexts.
\end{abstract}

Keywords Telepractice $\cdot$ Distance technology $\cdot$ Assessment $\cdot$ Intervention

\section{Introduction}

Promoting access to high-quality behavioral assessment and intervention is fundamental to the fields of education and behavior analysis. Yet barriers such as geographic location, limited access to local professionals and lack of resources can pose significant challenges in both the access and quality of behavioral services (Liptak et al. 2008; Mandell et al. 2010). To address these barriers, researchers in education and behavior analysis have eagerly engaged in adaptation of assessments (e.g., Machalicek et al. 2010; Wacker et al. 2013) and interventions (e.g., Neely, et al. 2019; Suess et al. 2014) to allow for online delivery and two-way audio-visual communication, i.e., telehealth.

Mandy Rispoli

mrispoli@purdue.edu

1 Department of Educational Studies, Purdue University, 100 N University Street, West Lafayette, IN 47907, USA

2 University of Oregon, Eugene, USA 
Telehealth or telemedicine is defined as "...the use of electronic or digital information and telecommunications technologies to support clinical healthcare, patient and professional health-related education and public health and health administration" (American Telemedicine Association 2017). Telehealth may include video and audio conferencing, chat messaging, wearable and sensor technologies, virtual reality, robotics and therapeutic gaming; however, in education, the primary thrust of research and practice has focused on the use of video and audio conferencing.

Telehealth has a long history of use in medicine beginning in 1964 on a closed circuit television system at the University of Nebraska School of Medicine (Bashshur and Shannon 2009) and thereafter moving into psychology (Baer et al. 1997). The development of personal computers and the use of telecomputing gave rise to the telemedicine approach and the use of asynchronous communication between provider and patient (Preston et al. 1992). Over the years, additional applications of telehealth have emerged including telepsychology, behavioral telehealth, telerehabilitation and telepractice. With advances in technology, some new capabilities in providing telehealth such as synchronous audiovisual feedback (Peterson et al. 2017), video sharing (Wilsie and Brestan-Knight 2012) and intercontinental communication (Barkaia et al. 2017).

The use of telehealth in educational and family home settings to deliver intervention to children with disabilities is also developing at a rapid rate (Tsami et al. 2019). The majority of educational applications have focused on training parents and teachers in research-based interventions to address the social communication and behavioral goals of young children with autism spectrum disorder (ASD, Ferguson et al. 2019). In early intensive applied behavior analysis, the use of telehealth has been a particularly attractive mechanism to relieve personnel shortages, heavy caseloads and the inability to pay or reimburse mileage (National Early Childhood Technical Assistance Center Annual Report 2010). However, the use of telehealth to deliver high-quality behavioral and educational services to populations beyond ASD is an important and emerging area of research (e.g. Haymes et al. 2015; Zyga et al. 2018).

In this two-part special issue, 11 studies synthesize, evaluate and extend our knowledge of telehealth as a means for delivering behavioral assessment and intervention within the education landscape. This special issue offers three literature reviews that offer evidence on the state of the science of telehealth with respect to behavioral intervention and training. McLay et al. (2020) present a narrative review and research quality appraisal of 10 studies evaluating telehealth interventions for sleep problems in children and adolescents. They synthesize this work with respect to intervention agent, intervention components, intervention delivery and intervention outcomes. Akemoglu et al. (2019) provide an evaluation of the quality of research on telehealth to teach parents to implement language and communication interventions with their children. The authors also present a narrative synthesis of the characteristics of telehealth parent interventions including technology used, training procedures applied and parent and child outcomes. Unholz-Bowden and colleagues (2020) synthesize thirty articles on caregiver telehealth training in behavior analytic services for families of children with AS and 
other disabilities. From the findings of this narrative review, the authors present a series of considerations for both researchers and providers interested in implementing telehealth with caregivers.

To improve educational and behavioral outcomes for children and youth with disabilities, research-based interventions should be consistently implemented with high fidelity. Unfortunately, training providers to implement practices with high fidelity can be prohibitive due to the number of children in need of services, specialist shortages and the financial cost of training (Love et al. 2013). In this special issue, two articles evaluate telehealth for training providers in behavioral assessment and intervention. Rios et al. (2020) explore how behavioral skills training, commonly used in face-to-face professional development, can be modified and delivered via telehealth. The authors used remote behavior skills training to teach 10 participants to implement functional analysis for challenging behavior. Results on participant acquisition of functional analysis procedures, generalization of those procedures and participant perspectives of the social validity of the telehealth behavioral skills training are presented.

Shire et al. (2020) compare face-to-face training with training delivered via telehealth on levels of treatment fidelity of the joint attention, symbolic play, engagement and regulation (JASPER) intervention. Through secondary data analysis from a larger randomized control trial, the authors examined interventionist implementation fidelity, child social communication outcomes and child-interventionist infractions across the face-to-face and telehealth training programs. Their findings are critical in demonstrating how high-quality telehealth training can change interventionist and child outcomes.

Telehealth offers great potential as a means of supporting intervention delivery and staff training in school settings. Rosenberg et al. (2020) extend telehealth to support and coaching for school personnel. Using a single-case design, the authors evaluate a bug-in-ear coaching model to support paraprofessional use of incidental teaching to promote adolescent students' self-advocacy skills. Results show an increase in paraprofessional fidelity of incidental teaching as well as increases in student self-advocacy phrases. This study provides a look at how telehealth allows for real-time coaching without disrupting classroom instruction or requiring additional adults in the classroom.

With an eye toward today's interconnected global landscape, two articles provide demonstrations of international telehealth to advance the implementation of high-quality behavioral services to children with ASD. Neely et al. (2020) develop and evaluate a videoconferencing training program for interventionists in Japan to implement incidental teaching with children with ASD with coaching from providers in the USA.

Zhu et al. (2020) investigate a telehealth intervention to teach professionals in China how to implement discrete trial teaching and incidental teaching with children with ASD. The authors evaluate the effect of delayed remote feedback on implementation fidelity and child outcomes for three interventionists. Together, these two papers extend our understanding of how telehealth can be extended across countries, cultures and even continents. 
In addition to supporting professionals' use of behavioral interventions with high fidelity, Morin and colleagues (2020) and Lerman and colleagues (2020) explore telehealth as a mechanism for supporting caregivers. Morin et al. develop and evaluate a telehealth delivered parent training intervention comprised of group training, parent self-monitoring and video self-reflection. Effects of the intervention on parent implementation and child responding are presented in a series of single-case experiments along with social validity data on acceptability and feasibility. As telehealth work extends to caregiver support, Lerman and colleagues highlight several issues that may arise when providing telehealth-based coaching to families of children with disabilities. Through case studies, they illustrate strategies for addressing these technical and clinical issues.

As technology and applications of telehealth continue to advance, it is critical to examine issues surrounding social validity of these practices. Chung and colleagues (2020) present a model for collecting a variety of social validity data for a telehealth parent training program for the youngest of learners. Through interviews, questionnaires and direct observation, the authors assessed early interventionists and caregivers' views on the program content, structure and telehealth delivery. Results highlight aspects of the program with high levels of provider and caregiver social validity as well as considerations for adaptations to telehealth-delivered programs in the future.

\section{Conclusion}

This special issue includes a variety of empirical demonstrations and systematic literature reviews that point to the potential of telehealth contributing to the fieldvalued outcomes of timely receipt of services, increased variety of service settings, improved care coordination across settings, improved access to expert consultation, improved family outcomes and decreased cost and improved efficiency of supervision. We encourage further research on these and related issues and believe the studies in this special issue offer positive exemplars of rigorous single-case research and findings across the literature.

\section{Compliance with Ethical Standards}

Conflict of interest All authors declare that they have no conflict of interest.

\section{References}

Akemoglu, Y., Muharib, R., \& Meadan, H. (2019). A systematic and quality review of parent-implemented language and communication interventions conducted via telepractice. Journal of Behavioral Education. https://doi.org/10.1007/s10864-019-09356-3.

Baer, L., Elford, R., \& Cukor, P. (1997). Telepsychiatry at forty: What have we learned? Harvard Review of Psychiatry, 5(1), 7-17. https://doi.org/10.3109/10673229709034720. 
Barkaia, A., Stokes, T. F., \& Mikiashvili, T. (2017). Intercontinental telehealth coaching of therapists to improve verbalizations by children with autism. Journal of Applied Behavior Analysis, 50(3), 582-589. https://doi.org/10.1002/jaba.391.

Bashshur, R. L., \& Shannon, C. W. (2009). History of telemedicine: Evolution, context, and transformation. New Rochelle: Mary Ann Liebert, Inc.

Chung, M. Y., Meadan, H., Snodgrass, M., Hacker, R., Sands, M., Adams, N. B., et al. (2020). Assessing the social validity of a telepractice training and coaching intervention. Journal of Behavioral Education. https://doi.org/10.1007/s10864-020-09372-8.

Ferguson, J., Craig, E. A., \& Dounavi, K. (2019). Telehealth as a model for providing behaviour analytic interventions to individuals with autism spectrum disorder: A systematic review. Journal of Autism and Developmental Disorders, 49(2), 582-616. https://doi.org/10.1007/s10803-018-3724-5.

Haymes, L. K., Storey, K., Maldonado, A., Post, M., \& Montgomery, J. (2015). Using applied behavior analysis and smart technology for meeting the health needs of individuals with intellectual disabilities. Developmental Neurorehabilitation, 18(6), 407-419. https://doi.org/10.3109/17518 423.2013.850750.

Lerman, D., O’Brien, M., Neely, L., Call, N. A., Tsami, L., Schieltz, K. M., et al. (2020). Remote coaching of caregivers via telehealth: Challenges and potential solutions. Journal of Behavioral Education. https://doi.org/10.1007/s10864-020-09378-2.

Liptak, G. S., Benzoni, L. B., Mruzek, D. W., et al. (2008). Disparities in diagnosis and access to health services for children withautism: Data from the National Survey of Children's Health. Journal of Developmental and Behavioral Pediatrics, 29(3), 152-160.

Love, S. M., Sanders, M. R., Metzler, C. W., Prinz, R. J., \& Kast, E. Z. (2013). Enhancing accessibility and engagement in evidence-based parenting programs to reduce maltreatment: Conversations with vulnerable parents. Journal of Public Child Welfare, 7(1), 20-38.

Machalicek, W., O'Reilly, M. F., Rispoli, M., et al. (2010). Training teachers to assess the challenging behaviors of students with autism using video tele-conferencing. Education and Training in Autism and Developmental Disabilities, 45(2), 203-215.

Mandell, D. S., Morales, K. H., Xie, M., et al. (2010). Age of diagnosis among medicaid-enrolled children with autism, 2001-2004. Psychiatric Services, 61(8), 822-829.

McLay, L., Sutherland, D., Machalicek, W., \& Sigafoos, J. (2020). Systematic review of telehealth interventions for the treatment of sleep problems in children and adolescents. Journal of Behavioral Education. https://doi.org/10.1007/s10864-020-09364-8.

Morin, K. L., Vannest, K. J., Hong, E. R., Haas, A., Nagro, S. A., Ganz, J. B., et al. (2020). Using remote delivery to train parents in video analysis procedures. Journal of Behavioral Education. https://doi. org/10.1007/s10864-019-09361-6.

National Early Childhood Technical Assistance Center (NECTAC). (2010). Part C SPP/APR 2010 Indicator Analyses-(FFY 2008). Retrieved from http://www.nectac.org/ pdfs/partc/partc_sppapr_10. pdf.

Neely, L., Hong, E. R., Kawamini, S., Umana, I., \& Kurz, I. (2020). Intercontinental telehealth to train Japanese interventionists in incidental teaching for children with autism. Journal of Behavioral Education. https://doi.org/10.1007/s10864-020-09377-3.

Neely, L., Rispoli, M., Boles, M., Morin, K., Gregori, E., Ninci, J., et al. (2019). Interventionist acquisition of incidental teaching using pyramidal training via telehealth. Behavior Modification, 43(5), 711-733. https://doi.org/10.1177/0145445518781770.

Peterson, K. M., Piazza, C. C., Luczynski, K. C., \& Fisher, W. W. (2017). Virtual-care delivery of applied-behavior-analysis services to children with autism spectrum disorder and related conditions. Behavior Analysis: Research and Practice, 17(4), 286-297. https://doi.org/10.1037/bar0000030.

Preston, J., Brown, F. W., \& Hartley, B. (1992). Using telemedicine to improve health care in distant areas. Hospital and Community Psychiatry, 43, 25-32.

Rios, D., Schenk, Y. A., Eldridge, R. R., \& Peterson, S. M. (2020). The effects of remote behavioral skills training on conducting functional analyses. Journal of Behavioral Education. https://doi. org/10.1007/s10864-020-09385-3.

Rosenberg, N. E., Artmam-Meeker, K., Kelly, E., \& Yang, X. (2020). The effects of bug-in-ear coaching package on implementation of incidental teaching by paraprofessionals in a K-12 school. Journal of Behavioral Education. https://doi.org/10.1007/s10864-020-09379-1.

Shire, S. Y., Worthman, L. B., Shih, W., \& Kasari, C. (2020). Comparison of face-to-face and remote support for interventionists learning to deliver JASPER intervention with children who have autism. Journal of Behavioral Education. https://doi.org/10.1007/s10864-020-09376-4. 
Suess, A. N., Romani, P. W., Wacker, D. P., Dyson, S. M., Kuhle, J. L., Lee, J. F., et al. (2014). Evaluating the treatment fidelity of parents who conduct in-home functional communication training with coaching via telehealth. Journal of Behavioral Education, 23(1), 34-59. https://doi.org/10.1007/ s10864-013-9183-3.

Tsami, L., Lerman, D., \& Toper, K. O. (2019). Effectiveness and acceptability of parent training via telehealth among families around the world. Journal of Applied Behavior Analysis, 52(4), 1113-1129. https://doi.org/10.1002/jaba.645.

Unholz-Bowden, E., McComas, J. J., McMaster, K. L., Girtler, S. N., Kolb, R. L., \& Shipchandler, A. (2020). Caregiver training via telehealth on behavioral procedures: A systematic review. Journal of Behavioral Education. https://doi.org/10.1007/s10864-020-09381-7.

Wacker, D. P., Lee, J. F., Dalmau, Y. C. P., Kopelman, T. G., Lindgren, S. D., Kuhle, J., et al. (2013). Conducting functional communication training via telehealth to reduce the problem behavior of young children with autism. Journal of Developmental and Physical Disabilities, 25(1), 35-48. https://doi.org/10.1007/s10882-012-9314-0.

Wilsie, C. C., \& Brestan-Knight, E. (2012). Using an online viewing system for parent-child interaction therapy consulting with professionals. Psychological Services, 9(2), 224-226. https://doi. org/10.1037/a0026183.

Zhu, J., Hua, Y., \& Yuan, C. (2020). Effects of remote performance feedback on procedural integrity of early intensive behavioral intervention programs in China. Journal of Behavioral Education. https:// doi.org/10.1007/s10864-020-09380-8.

Zyga, O., Russ, S. W., \& Dimitropoulos, A. (2018). The PRETEND program: Evaluating the feasibility of a remote parent-training intervention for children with Prader-Willi syndrome. American Journal on Intellectual and Developmental Disabilities, 123(6), 574-584. https://doi. org/10.1352/1944-7558-123.6.574.

Publisher's Note Springer Nature remains neutral with regard to jurisdictional claims in published maps and institutional affiliations. 